\title{
Theoretical issues on the African Stock Markets and Portfolio Performance
}

\author{
Odhiambo Odera \\ Department of Business Management, Masinde Muliro University of Science and Technology, \\ P.O.Box 190-50100 Kakamega, Kenya. \\ E-mail:oodera@yahoo.com
}

\begin{abstract}
The study discusses the theoretical issues surrounding the African stock markets and portfolio performance. It examines the issues underpinning the perception of market inefficiency in African stock markets. It has been proposed that the solution to problems faced by African stock markets is to integrate their stock exchanges by merging the stock exchanges. The study adopted an exploratory research design so as to gather preliminary information and help explore theoretical issues surrounding the African stock markets and portfolio performance.
\end{abstract}

Keywords: Africa, stock markets, regional integration, portfolio performance, savings, real sector

\section{Introduction}

Stock markets are able to positively influence economic growth through encouraging savings amongst individuals and providing avenues for firm financing. Liquid stock markets could improve the allocation of capital and enhancing prospects for long-term growth. However, the theory is ambiguous about the exact impacts of greater stock market liquidity on economic growth. By reducing the need for precautionary savings, increased stock market liquidity may have an adverse effect on the rate of economic growth. Magnusson and Wydick (2002), contends that the stock market is expected to accelerate economic growth by providing a boost to domestic savings and increasing the quantity and the quality of investment. Critics also point out that the actual operation of the pricing and takeover mechanism in well functioning stock markets lead to short term and lower rates of long term investment. This is because prices react very quickly to a variety of information influencing expectations on financial markets. Therefore, prices on the stock market tend to be highly volatile and enable profits within short periods. These problems are further magnified in developing countries especially sub-Saharan African economies with their weaker regulatory institutions and greater macroeconomic volatility. The higher degree of price volatility on stock markets in developing countries reduces the efficiency of the price signals in allocating investment resources. These serious limitations of the stock market have led many analysts to question the importance of the system in promoting economic growth in African countries.

Magnusson and Wydick (2002), used data from the eight largest African stock markets to test whether these markets meet the criterion of weak-form stock market efficiency with returns characterised by a random walk and then compared the results with similar tests on emerging stock markets in South-east Asia and Latin America. The results do not show that African countries can pass the high efficiency as the US markets but that they compare favourably to some Latin American and Asian markets.

According to Kenny and Moss (1998), the number of stock markets in African countries has doubled over the last 7 years. Although these markets remain small and illiquid, they are growing rapidly, and will become an increasingly important part of many African economies. They evaluated the common economic criticisms of African stock markets and the political pitfalls involved in their operation and concluded that 
the positive economic effects of bourses on African economies are far larger than any negative effects, and argue that the political costs can be mitigated while political benefits can also be gained. Smith et al. (2002) identified four categories of formal stock market in Africa as South Africa, medium-sized markets, small new markets which have experienced rapid growth, and small new markets which have yet to take off. Enisan and Olufisayo (2009) examined the long run and causal relationship between stock market development and economic growth for seven countries in sub-Saharan Africa. They found that the stock market development is cointegrated with economic growth in Egypt and South Africa suggesting that stock market development has a significant positive long run impact on economic growth. Based on these results, Enisan and Olufisayo argued that stock markets could help promote growth in Africa. However, to achieve this goal, African stock markets need to be further developed through appropriate regulatory and macroeconomic policies.

\section{Performance and Characteristics of African Stock Markets}

African Stock Markets have rapidly evolved over the last decade resulting in considerable development of the African capital markets (Piesse and Hearn, 2005). Prior to 1989, there were just five stock markets in Sub-Saharan Africa (SSA) and three in North Africa. Today there exist nineteen Sock exchanges in Africa (Yartey and Adjasi, 2007).Total market capitalization for African stock Markets increased from US\$113,423million to US\$244,672million between 1992 and 2002. This rapid development of Stock markets in Africa does mean that even the most advanced African Stock Markets are mature. In most of these markets, trading only occurs in only a few stocks which account for a considerable part of the total market capitalization. There also exist serious informational and disclosure deficiencies for other stocks. Supervision and monitoring by regulatory authorities is often far from adequate. According to Mlambo and Biekpe (2007), some of the African stock markets were established on the background of poor regulatory and legislative frameworks. This, among other things, explains why some of these markets lack the capacity to deal with capital market dynamics. Legislations to prevent insider trading are either inadequate or non-existent, and where they exist, enforcement is often poor. The inadequacy of insider trading laws on African stock markets has enhanced the perception that these markets are not efficient. However, IMF (2003) found that in a number of African countries, significant progress has been made, for instance through strengthening the regulatory and institutional framework governing private investment (Ghana, Mali, Mauritius, Mozambique, Tanzania, and Uganda) and fiscal capacity building (Burkina Faso, Mali, and Tanzania). However, much remains to be done; with institutions generally deeply rooted in a country's history and culture, domestic ownership is critical to ensure that reforms are tailored to meet specific regional conditions and circumstances.

Yartey and Adjasi (2007) observed that the indicators of Stock Market development show that African markets are small with few listed companies and low market capitalization. The African stock markets suffer from the problem of low liquidity, which means that it is harder to support a local market with its own trading system, market analysis, brokers etc since the business volume will simply be too low. According to Piesse and Hearn (2005), African stock markets have historically offered a limited, narrow range of products with the principle role of financial sector being the provision of the source of domestic funding to offset government budgetary deficits. Common factors still inhibiting stock market development include the lack of legal protection for investors and creditors. Other constraints are that most African Stock Exchanges have limited trading hours and are closely synchronous with other regional markets. As such, there is little domestic stock market culture and awareness. Trading in the majority of markets is overwhelmingly dominated by a handful of stocks, even if more securities are actually listed and bulk trading of a limited number of stocks in the smaller exchanges hinders activity on the domestic markets. Mlambo and Biekpe (2005) noted that due to the thin trading, investors may be forced to hold stocks even at a time when they want to close their positions or get out of the market. Their findings suggest that the contradictory evidence in the random walk tests of certain African stock markets could be partly a methodology problem especially in a thinly traded environment. But where they used individual stock returns, the effect of thin trading on the results was relatively minimal. 


\section{The Case for Regional Integration}

Jefferis and Smith (2005) observed that the size of the market is important, in that the larger markets are efficient for some or all of the period examined, while the smaller markets are not. For some countries, however, small size will always be a problem, bearing in mind the small size of many African economies.It has been proposed that the solution to problems faced by African stock markets was to integrate their stock exchanges and by merging stock exchanges (which is the extreme form of integration) could result in volumes multiplying with potentially the same overhead costs (Claessens et al., 2002). Merging African stock markets into a single regional exchange immediately is no doubt an ambitious and daunting task, given the associated institutional and financial cost complexities but it will be a powerful source and driver of capital flows to Africa. Such an exchange will also, if well structured, solve the current problems of illiquidity, small size, and fragmentation (Yartey and Adjasi, 2007).Integration is expected to solve the fragmentation problems of African stock exchanges since the number of national exchanges in an integrated market reduces. This promotes cost efficiency, and improves liquidity and price discovery. Investors can execute orders without routing through brokers and there is only one payment of listing fees in an integrated exchange. It also harnesses a pool of economic and human capital, the economic and human capital skills of various markets are brought to play in one single market. The market thus benefits from a rich and diverse pool of skills. Integration reduces complexities, since all trading, operations clearing and settlement systems are harmonized. It also improves surveillance and risk management, by enabling access to information in all market segments (Yartey and Adjasi, 2007).

One problem that has hindered successful stock market integration is nationalistic politics. African governments tend to view stock exchanges as national assets with pride just like national airlines (Moss, 2003). As a result, they are uncomfortable with transformations which lead to a reduction in the national touch. In addition, smaller economies tend to perceive the bigger economies as being domineering and fear that their exchanges will be overshadowed by the bigger exchanges with integration. These economies also fear that capital may be diverted away from them to the bigger economies with integration. For instance, Okeahalam (2001) reported that Botswana officials were uncomfortable with South Africa's virtual African exchange proposal due to the fear of capital flight towards Johannesburg Stock Exchange (JSE).There are important preconditions for successful regional approaches such as the legal harmonization (trading laws and accounting standards) and a liberalized trade regime. Integration requires that there are harmonized legislation, rules, listings, trading days, settlement, and reporting standards. This implies that for African stock markets to become integrated, the various national exchanges must adopt and/or harmonize their existing rules and systems. This can be potentially a long and arduous task for these exchanges. Even if trading rules and listing requirements are harmonized there is the issue of accounting and reporting standards. These standards tend to be based on national systems which in turn also depend on the colonial history of the countries. For instance, the Bourse Régionale des Valeurs Mobilières or the Regional Securities Exchange (BRVM) comprises of countries which adopted common standards following their common colonial past.

Integration cannot also be successful in the absence of automated systems. Currency convertibility is very important in an integrated exchange. An integrated exchange with a multiplicity of inconvertible currencies only compounds the administrative costs which integration itself seeks to remove. Here the advantages of having existing monetary unions, like the Western African Economic and Monetary Union (WAEMU) in the case of the BRVM preclude such problems. The experience of BRVM can teach us a number of lessons on stock market integration in Africa (Asea, 2003). First, it can take a very long time to build a regionally integrated exchange. Second, the fact that a regionally integrated exchange is established does not mean that it will be used effectively or that it will integrate the markets.

According to Piesse and Hearn (2005), regional market integration remains a viable approach to establishing functioning securities markets, assuming that there are sufficiently close institutional links. There has to be support for the benefits of integration, including more globally competitive markets and increasing liquidity levels, and from the African Stock Exchange Association (ASEA). Four principal 
regional bourses in Johannesburg, for the South African exchanges; Lagos, for West African region; Nairobi, for the East African exchanges and Cairo for Northern Africa were preparing the infrastructure to ensure integration by 2006. In the East Africa region, integrated trading floors and shared computerised networks and a central depository system were expected and listings requirements are common to the countries within SADC. Hearn and Piesse (2002) examined the extent of equity market integration using cointegration within the three dominant markets of Southern African Customs Union (SACU) that is South African, Botswana and Namibian.

\section{Portfolio Performance}

Aragon and Ferson (2007) defined portfolio performance at two broad levels; those that have investment ability if it generates returns that can be expected to exceed that of a benchmark. But a fund may dissipate its ability through trading costs or capture the rents to its ability through management fees. A fund that outperforms a benchmark is said to add value for investors. In many African organisations, a gap exists between the development of strategy and its successful implementation. Failure to fill this gap may ultimately result in strategy failure and the loss of competitive advantage, profits and employment. Project portfolio management (PPM) is theorised as a management methodology that links a portfolio of projects to business strategy. Bello (2005) used a sample of South African socially responsible mutual funds matched to randomly select conventional funds of similar net assets to investigate differences in characteristics of assets held, portfolio diversification and variable effects of diversification on investment performance. They found that socially responsible funds do not differ significantly from conventional funds in terms of any of these attributes. Moreover, the effect of diversification is not different between the two groups. Seo (2010) examined whether an integrated farm that owns both crops and livestock is more resilient under global warming than a specialized farm in crops. They explore how farmers choose one of the farm types and how the net revenue of each type varies across the range of climate in Africa. The results indicate that an integrated farm becomes relatively more profitable over specialised farms half a century from now and the impacts of climate change on integrated farms range from $9 \%$ loss to $27 \%$ gain depending on climate scenarios. They used behavioural models to capture portfolio diversification benefits that agro-economic model could not measure.

Mestry and Schmidt (2010) studied South African urban school principal's perception of the efficacy of using portfolios to assess their professional growth. Using a post structural lens to theorize portfolio use, interview data were examined to find out what themes consistently evolved when principals were engaged in self evaluating their own professional practice through a methodological framework of portfolio development. The findings revealed insights into the efficacy of the use of portfolios in the professional development of principals. According to Chan et al. (2009), an investor is usually concerned with how an individual portfolio performs. The research literature and industry practice offer up an array of benchmarks, including the stock index, and a logical case can be made for each of them. Therefore the issue is the frequency of agreement across benchmarks with respect to over or under-performance. Chan et al reported results when the methods were compared to abnormal returns over the portfolio's entire history. They calculated a portfolio's abnormal return over its full history by obtaining the difference between the geometric mean return on the portfolio and on the benchmark. They calculated all differences in abnormal returns across methods and counted the frequency of differences that exceed a certain threshold level out of the total possible comparisons. For all portfolios in the overall sample period the methods agreed on the sign of abnormal returns. Given the emphasis on performance, a few quarters of poor results can sour relations between a money manager and clients. These results suggest that the choice of benchmarking procedure can make or break a money manager's reputation (Chan et al., 2009). Stutzer (2000) introduced the portfolio performance index which is based on the behavioural hypothesis that investors aim to minimize the probability that the excess returns over a given threshold will be negative. The Omega ratio introduced by Keating and Shadwick (2002) was expressed as the ratio of the gains with respect to some threshold to the loss with respect to the same threshold. The drawbacks of these measures include; the ranking of portfolios based on most of these measures depends heavily on the choice of a threshold, almost 
all of these measures take into account only downside risk, the upside return potential is not appreciated and all these alternative performance measures lack any solid theoretical underpinning (like the Sharpe ratio which is based on the expected utility theory, the cornerstone of the modern finance).

Ferson (2010) reviewed literature on investment performance evaluation and summarized the significant forces and contributions that have brought this field of research to its current state of knowledge while Aragon and Ferson (2007) provided a review of the methods for measuring portfolio performance and the evidence on the performance of professionally managed investment portfolios. Dybvig et al. (2010) analysed the optimal contract for a portfolio manager who can exert effort to improve the quality of a private signal about future market prices. They assumed complete markets over states distinguished by asset payoffs and place no restrictions on the form of the contract. They showed that trading restrictions are essential because they prevent the manager from undoing the incentive effects of performance-based fees and provided conditions under which simple benchmarking emerges as optimal compensation.

According to Mensah (2003), tests generally support weak-form efficiency (i.e. past prices cannot be used to predict future prices). Few portfolio managers are able to beat the market and do not do so with any consistency. Aragon and Ferson (2007) discussed evidence from conditional performance evaluation such as survivorship which creates a number of potential problems affecting both the average levels of performance and the apparent persistence in performance. Much of the empirical evidence on performance persistence for mutual funds suggests a positive relation between the future and past performance, and concentrate in the poorly performing funds. Poor performance may be persistent. Del Guercio and Tkac (2002) found that mutual fund investors pay more attention to simple measures of relative return than to more complex measures like alpha, in directing their new money flows.

\section{Savings and the Real Sector of the African Economies}

According to World Bank estimates migrants remittances reached \$ 21 billion in SSA in 2008. Baldé (2011) analyzed comparatively the effectiveness of remittances and foreign aid in promoting savings and investments. They found that both remittances and foreign aid positively and significantly influence savings and investments in SSA, meaning that remittances in SSA are not only and entirely spent in basic consumption needs. They also find that remittances, by being received directly by people in need would serve more households' interests and be more effective in favouring economic development that foreign aid. However, when efficiently used in a good institutional, political and economic environment, foreign aid can act as a complement to remittances by allowing vulnerable households to have income above the threshold subsistence' level so they use a larger share of remittance for savings and investments purposes. Odhiambo (2009) examined the direction of causality between savings and economic growth in South Africa. They find a bi-directional causality between savings and economic growth prevailing in the short run and a distinct unidirectional causal flow from economic growth to savings in the long run. Growth led savings is found to predominate in South Africa and recommends that policies should be geared towards achieving both higher savings and economic growth so as to boost investors confidence and attract foreign capital inflow.

According to Kelly and Mavrotas (2002), most African countries often lack an appropriate financial sector, which provides incentives for individuals to save and acts as an efficient intermediary to convert these savings into credit for borrowers. Gyimah-Brempong (2002) used panel data from African countries and a dynamic panel estimator to investigate the effects of corruption on economic growth and income distribution. Corruption was found to decrease economic growth directly and indirectly through decreased investment in physical capital. The combined effect of decreased income growth and increased inequality suggests that corruption hurts the poor more than the rich in African countries.

Collier and Gunning (1999) observed that Africa has demographic characteristics which may predispose it to slow growth such as life expectancy has historically been low, with the population in a high-fertility, high infant-mortality equilibrium. In Africa, AIDS is a heterosexual disease and during the 1980s in parts 
of Africa it spread rapidly across the population before the risks became apparent, with up to 20-25 percent of adults now Human Immunodeficiency Virus (HIV)-positive in some countries (World Bank, 1997). Ndikumana and Boyce (2002) investigated the determinants of capital flight from 30 sub-Saharan African countries, including 24 countries classified as severely indebted low-income countries, for the period 19701996. They estimate that for every dollar of external borrowing in the region, roughly 80 cents flowed back as capital flight in the same year. Iyoha and Oriakhi (2002) observed that while there is no consensus on a single cause of Africa's economic predicament, the currently identified factors include the continent's colonial legacy, its backward technology, export enclavism, extremely disadvantageous geography and climate, demography, social conditions, ethnic and tribal divisions, unfavourable initial conditions, deficient infrastructure, lack of financial depth, macroeconomic policy mistakes, hostile external environment, and dependence on primary commodity exportation.

\section{Methodology}

The study adopted an exploratory research design so as to explore the pertinent theoretical issues surrounding the African Stock Markets and portfolio performance. Exploratory research was used to gather preliminary information so as to help define problems, suggest hypotheses and to help determine the best research design, data collection method and sample selection methods. The study relied on reviewing available literature and the results of the study can provide significant insight into the problems facing African Stock Markets and Portfolio performance. For example Piesse and Hearn (2005) suggested that the appropriate method of examining volatility transmission between African stock market indices is the EGARCH model suggested by Nelson (1991), because it allows a more flexible dynamic lag structure and does not require symmetry. Domestic macroeconomic influences commonly found within emerging market countries, such as extreme variations in exchange rates and high inflation, can have significant effects on stock price indices (Choudry, 2001).

Econometric techniques have also been used extensively to examine the relationship between macroeconomic phenomena and securities market integration. (Maysami et al., 2000; Phylaktis, 1999; Huang et al., 2000).Kelly and Mavrotas (2002) used econometric methods such as the panel unit root test (Dickey and Fuller, 1979) and cointegration tests to enable them determine the long run structure of savings in a dynamic setting, avoiding the well known problems involved in using static cointegration testing, and the problems of the sensitivity of cointegration tests to low-powered stationarity tests involved in time series analysis. Most importantly, these innovative panel data techniques allow for heterogeneity in coefficients and dynamics across countries, and allow testing directly for the existence of long run equilibrium saving functions.

Hearn and Piesse (2002) tested the hypothesis of market integration using a cointegration approach. Markets that are found to be integrated are then tested for evidence of Granger causality through an error correction mechanism. Results obtained using VAR modelling techniques are compared to those using an ARDL model. While results lend support to existing trade, macroeconomic and developmental linkages and effects between and within the countries, there is some evidence for the presence of a regional factor common to African Emerging Markets that explains causality from Namibia to South Africa.

\section{Conclusion}

Yartey and Adjasi (2007) discussed the results from the previous studies which show that African stock markets are small, illiquid, with infrastructural bottlenecks and weak regulatory institutions. Despite these problems, stock markets in Africa have helped in the financing of the growth of large corporations but there is little evidence of broader economic benefits. Jefferies and Smith (2005) suggests that regional stock markets may be a way forward, not just to benefit from economies of scale but also to improve pricing efficiency. In addition to policies aimed at increasing the size of stock markets, other institutional reforms can help to improve efficiency. These include innovations such as electronic trading systems, allowing free access to foreign investors (to improve liquidity), improving the dissemination of information relating to 
Research Journal of Finance and Accounting ISSN 2222-1697 (Paper) ISSN 2222-2847 (Online)

Vol 3, No 3, 2012

listed companies, improving the speed and efficiency of settlement, and changing the legal framework where necessary to ensure adherence to the best international standards. According to Magnusson and Wydick (2002) test results for weak-form efficiency in the emerging African stock markets compare favourably with those performed on other emerging stock markets.

Piesse and Hearn (2005) concluded that in a number of African countries, the emphasis on growth and development has shifted from a bank-based system to one that is dependent on capital markets as a source of finance for the business sector. This has resulted in the establishment of a number of new stock exchanges and the restructuring and reform of many of the existing ones. Although still highly illiquid, and with only a limited culture of participation by the business and investment community, many of these appear to be making progress. According to Mensah (2003), African capital markets will not develop unless both issuers and investors believe that securities are fairly priced and the persistence of inefficiency means that investors are not using all information at their disposal in setting security prices, i.e. expectations are not "rational". African regulators are poorly resourced and as such they have poor market surveillance, limited analytical and investigative capacities. Mensah concludes that the majority of the African Stock markets except for South African Stock Exchange, exhibit immature markets and market efficiency are low. Low market professionalism leads to market inefficiencies and low returns are realized to active management. Therefore, African Stock Markets need far more professionalism and better regulatory enforcement in order to improve stock market efficiency, without which market efficiency will remain elusive.

\section{References}

Aragon G. O. and Ferson W. E. (2007). Portfolio Performance Evaluation, Foundations and Trends in Finance Vol. 2, No. 2. http://dx.doi.org/10.1561/0500000015

Asea, P. (2003). "Promoting Regional Financial Market Integration" Presented at the African Capital Markets Development Workshop, Johannesburg, South Africa.

Baldé, Y. (2011). The Impact of Remittances and Foreign Aid on Savings/Investment in Sub-Saharan Africa. African Development Review: Vol. 23 Issue 2, p 247-262 http://dx.doi.org/10.1111/j.14678268.2011.00284.x x

Bello, Z. Y. (2005). Socially responsible investing and portfolio diversification. The Journal of Financial Research, XXVIII(1), 41-57. http://dx.doi.org/10.1111/j.1475-6803.2005.00113.X

Chan L. K. C., Dimmock S. G.and Lakonishok J. (2009). Benchmarking money manager performance: Issues and evidence, Review of Financial Studies Vol. 22, Issue11. http://dx.doi.org/10.1093/rfs/hhp016

Choudhry T. (2001). Inflation and rates of return on stocks: evidence from high inflation countries, Journal of International Markets, Institutions and Money, 11, 75-96 http://dx.doi.org/10.1016/S10424431(00)00037-8

Claessens S., Klingebiel D. and Schmukler, S. C. (2002). "Explaining the Migration of Stocks from Exchanges in Emerging Economies to International Centers," World Bank Working Paper No. 2816, Washington: The World Bank.

Collier P. and Gunning W.J. (1999). Why Has Africa Grown Slowly? The Journal of Economic Perspectives, Vol. 13, No. 3. pp. 3-22. http://dx.doi.org/10.1257/jep.13.3.3

Del Guercio, D. and Tkac, P. (2002). The determinants of the flows of funds of managed portfolios: Mutual funds vs. pension funds, Journal of Financial and Quantitative Analysis 37.

Dickey, D. A. and W. Fuller. (1979). "Distribution of the Estimates for Autoregressive Time Series with a Unit Root."J. Am. Stat. Assoc., 74427-431. http://dx.doi.org/10.2307/2286348

Dybvig P. H., Farnsworth H. K. and Carpenter J. N. (2010). Portfolio Performance and Agency, Review of Financial Studies Volume23, Issue1. http://dx.doi.org/10.1093/rfs/hhp056 
Research Journal of Finance and Accounting ISSN 2222-1697 (Paper) ISSN 2222-2847 (Online)

Vol 3, No 3, 2012

Enisan A. A. and Olufisayo A. O. (2009). Stock market development and economic growth: Evidence from seven sub-Sahara African countries, Journal of Economics and Business Vol. 61, Issue 2 http://dx.doi.org/10.1016/j.jeconbus.2008.05.001

Ferson W. E. (2010). Investment Performance Evaluation, Annual Review of Financial Economics_Vol. 2, Issue 1. http://dx.doi.org/10.1146/annurev-financial-120209-134007

Gyimah-Brempong K. (2002). Corruption, economic growth, and income inequality in Africa Economics of Governance 3: 183-209. http://dx.doi.org/10.1007/s101010200045

Hearn B. and Piesse J. (2002). Equity Market Integration versus Segmentation in Three Dominant Markets of the Southern African Customs Union: Cointegration and Causality Tests, Applied Economics, Vol. 14. No. 1.

Huang B-N, Yang C-W and Hu J. (2000). Causality and cointegration of stock markets among the United States, Japan, and the South China Growth Triangle, International Review of Financial. Analysis, 9:3, 28197. http://dx.doi.org/10.1016/S1057-5219(00)00031-4

Iyoha M. A. and Oriakhi D. (2002). Explaining African Economic Growth Performance: The Case of Nigeria www.gdnet.org/CMS

Jefferis K. and Smith G. (2005). The Changing Efficiency of African Stock Markets South African Journal of Economics Vol. 73, Issue 1. http://dx.doi.org/10.1111/j.1813-6982.2005.00004.x

Keating C. and Shadwick W. F. (2002). A Universal Performance Measure; The Finance Development Centre London, www.isda.org/c_and_a/pdf/GammaPub.pdf

Kelly R. and Mavrotas G. (2002). Savings and Financial Sector Development: Panel Cointegration Evidence from Africa. World Institute for Development Economics Research Discussion Paper No. 2003/12. http://dx.doi.org/10.1016/S0305-750X(98)00019-9

Kenny C. J. and Moss T. J. (1998). Stock Markets in Africa: Emerging lions or white elephants? World Development Vol. 26, Issue 5. http://dx.doi.org/10.1016/S0305-750X(98)00019-9

Magnusson M. and Wydick B. (2002). How efficient are Africa's Emerging Stock Markets? Journal of Development Studies Vol. 38, Issue 4. http://dx.doi.org/10.1080/00220380412331322441

Mensah S. (2003). The Essentials of an Efficient Market and Implications for Investors, Firms and Regulators UNECA Workshop on African Capital Markets Development, Johannesburg, SA.

Mestry, R., \& Schmidt, M. (2010). Portfolio Assessment as a Tool for Promoting Professional Development of School Principals: A South African Perspective. [Article]. Education \& Urban Society, 42(3), 352-373. http://dx.doi.org/10.1177/0013124509357694

Mlambo, C. and Biekpe, N. (2007). The efficient market hypothesis: Evidence from ten African stock markets; Investment Analysts Journal - No. 66

Mlambo, C. and Biekpe, N. (2005). Thin Trading on African Stock Markets: Implications for Market Efficiency Testing" Investment Analyst Journal No 61.

Moss, T. (2003). “Adventure Capitalism: Globalization and the Political Economy of Stock Markets in Africa," London: Palgrave Macmillan.

Nelson D. (1991). Conditional Heteroskedasticity in Asset Returns: A New Approach. Econometrica, 59:2, 347-70 http://dx.doi.org/10.2307/2938260

Ndikumana, L. and Boyce, J. K. (2002). "Public Debts and Private Assets: Explaining Capital Flight from Sub-Saharan African Countries". Economics Department Working Paper Series. Paper 91. ScholarWorks@UMass Amherst

Maysami R and Koh T. (2000). A vector error correction model of the Singapore stock market, Journal of International Money and Finance, 9, 79-6 http://dx.doi.org/10.1016/S1059-0560(99)00042-8

Phylaktis K. (1999). Capital Market integration in the Pacific Basin region: an impulse response analysis, Journal of International Money and Finance, 18, 267-87 
Research Journal of Finance and Accounting ISSN 2222-1697 (Paper) ISSN 2222-2847 (Online)

Vol 3, No 3, 2012

\section{http://dx.doi.org/10.1016/S0261-5606(98)00046-1}

Odhiambo, N. M.(2009) Savings and economic growth in South Africa: A multivariate causality test. Journal of Policy Modeling; Vol. 31 Issue 5, p708-718 http://dx.doi.org/10.1016/j.jpolmod.2009.04.001

Okeahalam, C., C. (2001). "Strategic Alliances and Mergers of Financial Exchanges: The Case of the SADC," presented at the Fourth Annual Conference of the Centre for the Study of African Economies, Oxford University, March 19-31. http://dx.doi.org/10.1080/03057070500035703

Piesse J. and Hearn B. (2005). Regional Integration of Equity Markets in Sub-Saharan Africa. South African Journal of Economics Volume 73, Issue 1. http://dx.doi.org/10.1111/j.1813-6982.2005.00003.x

Seo, S. N. (2010). Is an integrated farm more resilient against climate change? A micro-econometric analysis of portfolio diversification in African agriculture. [Article]. Food Policy, 35(1), 32-40. http://dx.doi.org/10.1016/j.foodpol.2011.03.003

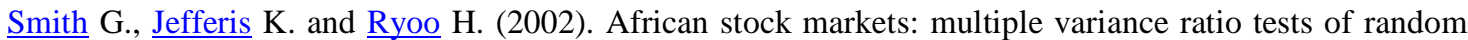
walks Applied Financial Economics Vol. 12, Issue 7. http://dx.doi.org/10.1080/09603100010009957

Stutzer M. (2000). A Portfolio Performance Index. Financial Analysts Journal Vol. 56 Issue 3. http://dx.doi.org/10.2469/faj.v56.n3.2360

Yartey C.O.and Adjasi C.K. (2007). Stock Market Development in Sub Saharan Africa: Critical Issues and Challenges. International Monetary Fund working paper No. wp/07/209.

World Bank (1997). Confronting Aids, Policy Research Report. Oxford University Press. 
This academic article was published by The International Institute for Science, Technology and Education (IISTE). The IISTE is a pioneer in the Open Access Publishing service based in the U.S. and Europe. The aim of the institute is Accelerating Global Knowledge Sharing.

More information about the publisher can be found in the IISTE's homepage: http://www.iiste.org

The IISTE is currently hosting more than 30 peer-reviewed academic journals and collaborating with academic institutions around the world. Prospective authors of IISTE journals can find the submission instruction on the following page: http://www.iiste.org/Journals/

The IISTE editorial team promises to the review and publish all the qualified submissions in a fast manner. All the journals articles are available online to the readers all over the world without financial, legal, or technical barriers other than those inseparable from gaining access to the internet itself. Printed version of the journals is also available upon request of readers and authors.

\section{IISTE Knowledge Sharing Partners}

EBSCO, Index Copernicus, Ulrich's Periodicals Directory, JournalTOCS, PKP Open Archives Harvester, Bielefeld Academic Search Engine, Elektronische Zeitschriftenbibliothek EZB, Open J-Gate, OCLC WorldCat, Universe Digtial Library, NewJour, Google Scholar



\section{Ounachener}

JournalTOCs

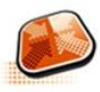

PKP | PUBLIC KNOWLEDGE PROJECT
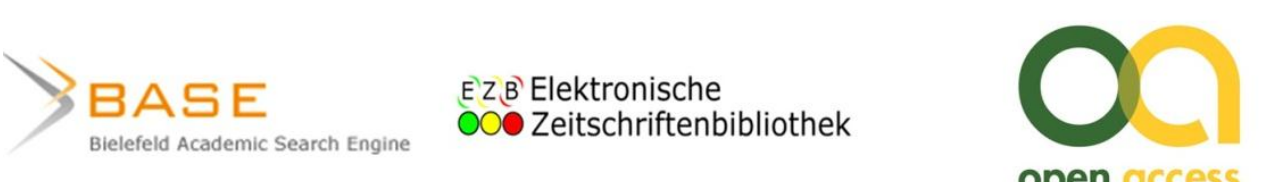

open access



Connected.
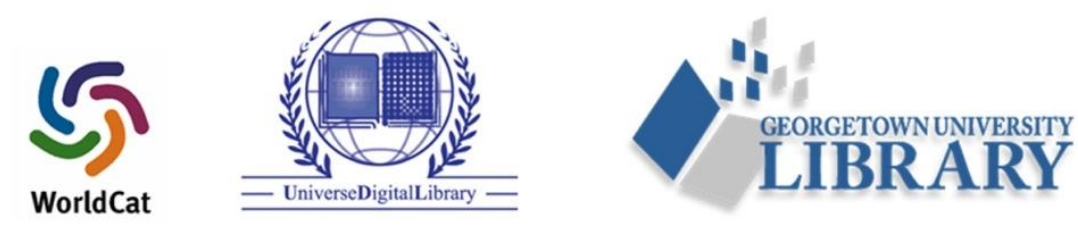